\title{
CONTENT, BIOAVAILABILITY, BIOCON WERSION AND ANTIOXIDANT CTIIVITIES OF CAROTENOIDS IN SOME SRI LANKAN FRUITS AND GREEN LEAFY VEGETABLES
}

By

IJIDUMAALA(GAIAI (GAVAGE KTCIANE)R1 KA 
CONTENT, BIOAVAILABILITY, BIOCONVERSION AND ANTIOXIDANT ACTIVITIES OF CAROTENOIDS IN SOME SRI LANKAN FRUITS AND GREEN LEAFY

\author{
VEGETABLES
}

BY

UDUMALAGALA GAMAGE CHANDRIKA B.Sc. Hons., M.Phil., M.IChem., C.Chem.

Thesis submitted to the University of Sri Jayewardenepura for the award of the Degree of Doctor of Philosophy in Biochemistry on $30^{\text {th }}$ June 2004. 


\section{DECLARATION BY THE CANIDIDATE}

The work described in this thesis was carried out by me under the supervision of

Professor E. R. Jansz (Senior Professor. Head of the Department of Biochemistry. Faculty of Medical Sciences, University of Sri Jayewardencpura) and Professor N. D. Warnasuriya (Dean of the Faculty of Medical Sciences. University of Sri Jayewardenepura) and a report on this has not been submitted in whole or in part to any University or any other institution for another Degree/Diploma.

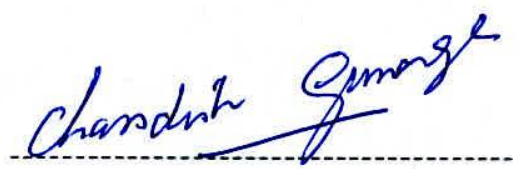

Udumalagala Gamage Chandrika

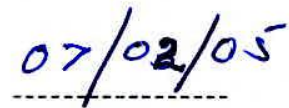

Date 


\section{DECLARATION OF THE SUPERVISORS}

We certify that the above statement made by the candidate is true and that this thesis is suitable for submission to the University for the purpose of evaluation.

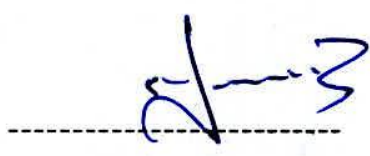

Professor E. R. Jansz (Supervisor)

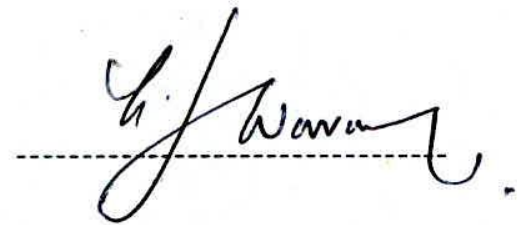

Professor N. D. Warnasuriya (Supervisor)
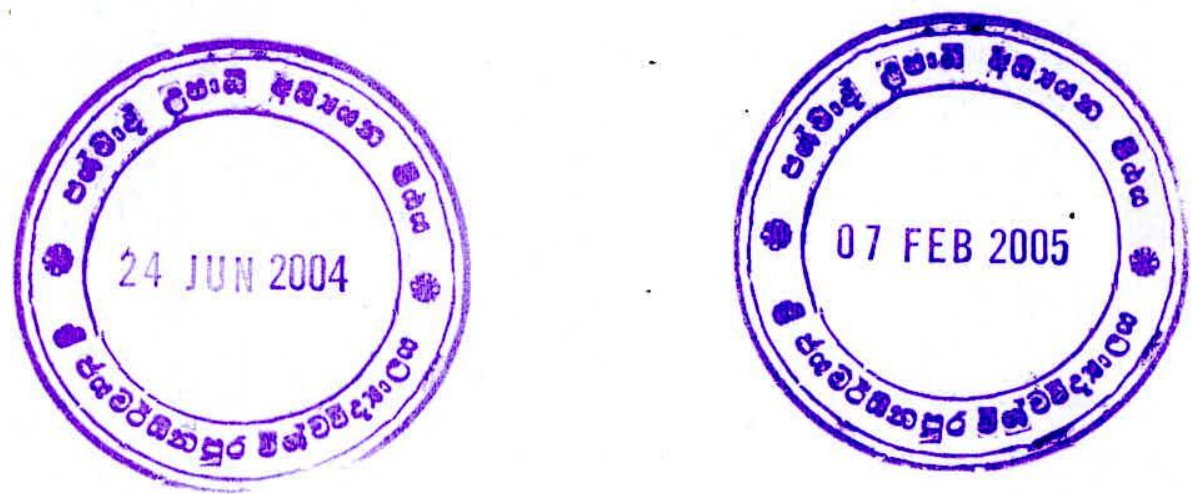


\section{TABLE OF CONTENTS}

I LIST OF TABLES

II LIST OF FIGURES

III LIST OF PLATES

IV ABBREVIATIONS

V ACKNOWLEDGEMENTS

VI ABSTRACT

1. INTRODUCTION

\subsection{General introduction}

1.1.1 Functional importance of Vitamin A

1.1.2 Sources of vitamin A

1.1.3 Measurement of vitamin $A$

1.1.4 Vitamin A deficiency

1.1.4.1 History of Vitamin A deficiency in Sri Lanka

1.1.5 Prevention of vitamin A deficiency

1.1.5.1 Food based strategies to reduce vitamin A deficiency

1.1.5.2 Prevention of vitamin A deficiency in Sri Lanka

1.1.6 Other health benefits of carotenoids

\subsection{Justification for study}

\subsection{Scope of study}




\section{REVIEW OF LITRETURE}

\subsection{Carotenoids}

2.1.1 Occurrence of carotenoids

\subsubsection{Chemistry of carotenoids}

2.1.3 Biosynthesis and metabolism of carotenoids

2.1.4 Chemical characteristics of natural carotenoids

2.1.4.1 Common carotene

2.1.4.2 Common xanthophylls

2.1.t.3 Cis-isomers

2.1.4.4 Carotenol esters

2.1.5 Factors influencing carotenoid composition in fruits and vegetables

2.1.5.1 Stage of maturity

2.1.5.2 Cultivar or varietal differences

2.1.5.3 Climatic or geographic effects

2.1.5.4 Changes on processing and storage

2.1.6 Functions of carotenoids in human health

2.1.6.1 Carotenoids as pro-vitamin $A$

2.1.6.2 Use of carotenoids as markers for dietary practices

2.1.6.3 Carotenoids as antioxidants

2.1.6.4 Carotenoids in the macular region of the retina

\subsubsection{Bioavailability of carotenoids}

2.1.7.1 Factors affecting bioavailability

2.1.7.2 Influence of processing on carotenoids bioavailability 
2.1.7.3 Splitting on carotenoids by beta carotene

15-15' dioxygenase enzyme

2.1.8 Problems in carotenoid analysis

\section{$2.2 \quad$ Vitamin A}

2.2.1 Digestion and absorption

2.2.2 Transport to the liver

2.2.3 Metabolism in the liver

2.2.4 Transport to other cells

2.2.5 Gene function and retinoids

2.2.6 Functions of vitamin A

\subsubsection{Vision}

2.2.6.2 Cellular differentiation

2.2.6.3 Glycoprotein and glycosaminoglycan synthesis

2.2.6.4 Embryogenesis

2.2.7 Assessing vitamin A deficiency as a public health problem

2.2.7.1 Assessment methodologies and indicators

2.1.7.2 Vitamin A Toxicity

\subsection{Raw materials used}

\subsubsection{Fruits}

2.3.2 Green leafy vegetables

\subsection{Animal studies}

2.4.1 Justification of use of rats

2.4.2 Formulation of animal diets 
2.4.3 Number and grouping of animals

2.5 Theory of In vitro digestion method for bioaccesibility

2.5.1 Validation of the in vitro digestion method

\section{MATERIALS AND METHODS}

\subsection{Materials}

3.1.1 Water

3.1.2 Solvents

3.1.3 Special chemicals

3.1.4 Plant material

\subsection{Method}

3.2.1 Analysis of carotenoids

3.2.1.1 Papaya (Carica papayca L.)

3.2.1.2 Palmyrah (Borassus flabellifer L.)

3.2.1.3 Jakfruit (Artocurpus heterophyllus)

3.2.1.4 Lavalu (Chrysophyllum roxhbergii)

3.2.1.5 Beli fruit (Aegle marmelos)

3.2.1.6 Green leafy vegetables (GLV) 


\subsubsection{General methods}

3.2.2.1 Identification of carotenoids

\subsubsection{Chemical tests}

\subsubsection{Quantification of carotenoids}

3.2.2.4 Calculation of carotenoid concentration

\subsubsection{Determination of moisture content}

3.2.3 In vivo bioavailability and bioconversion studies

in rats (animal studies)

\subsubsection{General methods}

3.2.3.2 Effect of bioavailability and bioconversion of pro-vitamin A carotenoids on some selected fruits and vegetables

3.2.3.3 Analysis of constituents in serum and liver

3.2.4 Effect of in vivo lipid peroxidation on heart from papaya and palmyrah using animal models

\subsubsection{Animal studies}

\subsubsection{General methods}

3.2.5 In vitro accessibility of pro-vitamin A carotenoids

3.2.5.1 Investigation of domestic cooking on in vitro carotenoids accessibility

\subsubsection{Statistical analysis}




\section{RESULTS}

\subsection{Overview}

\subsection{Papaya (Carica papaya) fruit pulp)}

4.1.1 Qualitative analysis of papaya (Solo) collected from Brasil

4.1.1.1 Isolation of carotenoids using Open Column Chromatography (OCC)

4.1.1.2 Identification of carotenoids

4.1.2 Qualitative and Quantitative (spectrophotometry) analysis of papaya (yellow-and red fleshed) collected in Sri Lanka

4.1.2.1 Isolation and identitication of carotenoids using Medium Pressure Liquid Chromatography (MPLC)

4.1.2.2 In vivo bioavailability and bioconversion of provitamin $\mathrm{A}$ carotenoids to vitamin $\mathrm{A}$ using rat model.

4.1.2.3 In-vivo cardiac lipid peroxidation

\subsection{Palmyrah (Borassus flabellifer L.) fruit pulp}

4.2.I Isolation, identification and quantification of carotenoids

4.2.2 In vivo bioavailability and bioconversion of palmyrah carotenoids

4.2.3 In vivo cardiac lipid peroxidation

\subsection{Jak fruits (Artocarpus heterophyllus) kernel}

4.3.1 Qualitative and quantitative analysis of carotenoids

4.3.1.1 Isolation of carotenoids using MPLC 
4.3.1.2 Thin Layer Chromatography (TLC)

4.3.1.3 Identification

4.3.1.4 Quantification

4.3.2 In vivo bioavailability and bioconversion of

pro-vitamin A carotenoids to vitamin A

4.4 Lavalu (Chrysophyllum roxhbergii S. Don) fruit pulp

4.4.1 Qualitative analysis

4.4.1.1 Isolation of carotenoids using Open Column

Chromatography (OC()

4.4.1.2 Chemical tests

4.1.1.3 Identification

4.1.1.4 HPLC quantification

(1) Preparation of standard solutions

(2) Calcultion

4.5 Beal (Aegle marmelos) fruit pulp

\subsubsection{Qualitative analysis}

4.5.1.1 Isolation of carotenoids using OCC

\subsection{Green leafy vegetables}

4.6.1 Qualitative analysis of kathurumurunga

4.6.2 Qualitative analysis of leafy vegetables

4.6.2.1 Qualitative carotenoid analysis of kathurumurunga and mukunuwanna carried out in Brasil 
4.6.2.2 Quantification of $\beta$-carotene and lutein in green leafy vegetables collected from Sri Lanka

4.6.2.3 Comparison of the results of green leafy vegetables studied in three different laboratories

4.6.3 In vitro bioavailability studies

4.6.3.1 Content and in vitro bioavailability of all trans $\beta$-carotene in cooked green leafy vegetables

4.6.3.2 Content and in vitro accessibility of 9-cis- $\beta$-carotene in cooked green leafy vegetables

4.6.3.3 In vitro accessible all-trans- $\beta$-carotene in vegetable portions and their estimated vitamin A contributions

4.6.3.1 Content and in vitro bioavailability of lutein in cooked green leafy vegetables

4.6.4 In vivo bioavailability and bioconversion of pro-vitamin A carotenoids to vitamin A

\section{DISCUSSION}

6. REFERENCES

APPENDIX I Publications and Communications from this study

APPENDIX II UV/Visible spectra of major carotenoids of papaya (solo)

collected from Brazil

APPENDIX $111 \quad$ UV/Visible spectra of major carotenoids from papaya

(yellow- and red-fleshed) collected from Sri Lanka 
APPENDIX IV UV/Visible spectra of major carotenoids of lavalu APPENDIX V HPLC chromatogram of isolated beli carotenoids APPENDIX VI UV/Visible spectra of major carotenoids of kathurumurunga (Sasbania grandiflora)

APPENDIX V Curriculum vitae 


\section{LIST OF TABLES}

Table 1.1 Recommended daily intakes (RDI) of vitamin $A(R E)$ in $\mu g$ per day to provide basal requirements of safe levels

Table 2.1 Relative pro-vitamin A activity of various carotenoids

Table 2.2 Extra cellular transport molecules for retinoids and carotenoids

Table 2.3. Nutritive values of fruits studied

Table 2.4 Composition of green leafy vegetables (mukunuwanna, manioc. gotukola and kathurumurunga)

Table 2.5 Composition of green leafy vegetables (sarana. thampala and nivithi)

Table 2.6 Estimated vitamin A activities in vegetable and fruit diets using different methods

Table $3.1 \quad$ WHO recommended feed formula (Sabourdy, 1998)

Table 3.2 Feeding schedule for supplementation (mukunuwanna) of experimental rats

Table 4.1 Properties of the major carotenoids of papaya (Solo)

Table 4.2 Major pro-vitamin A and non-provitamin A carotenoids in fruits of yellow- and red-fleshed papaya (Carica papaya L.)

Table 4.3 Serum vitamin A in Wistar rats given papaya

Table 4.4 Liver vitamin $A$ and $\beta$-carotene in rats given papaya incorporated to standard diet.

Table 4.5 Major pro-vitamin A and non-pro-vitamin A carotenoids in fruits of palmyrah (Hambantota sample)

Table 4.6 Serum vitamin A in Wistar rats given palmyrah - 
Table 4.7 Major pro-vitamin A and non-pro-vitamin A carotenoids in jakfruits (Artocarpus heterophy/lus.)

Table 4.8 Quantification of major pro-vitamin A and non-pro-vitamin A carotenoids in jakfruits (Arlocarpus heterophy/lus)

Table 4.9 Effects on serum and liver retinol concentrations (mean \pm SD) of rats supplemented with jakfruit kernel

Table $4.10 \quad$ Properties of lavalu carotenoids

Table 4.11 Carotenoid concentrations in lavalu (C'hysophy/lum roxhburgii)

Table 4.12 Wavelengths of maximum absorption $\left(\lambda_{\text {max }}\right)$ of the carotenoids of kathurumurunga

Table 4.13 Carotenoid concentrations in mukunuwanna (Alternathera sessilis) and kathurumurunga (Sesbania grandiflora)

Table 4.14 Lutein and $\beta$-carotene content (mean \pm SD) of selected green leafy vegetables

Table 4.15 $\beta$-carotene content of mukunuwanna and kathurumurunga studied in different laboratories

Table 4.16 Total content and in vitro accessibility of all-rrans-beta carotene in traditionally cooked vegetables ("malluma")

Table 4.17 Total content and in vitro accessibility of all-trans-beta carotene in traditionally cooked vegetables (stir-fried)

Table 4.18 Total content and in vitro accessibility of all-truns-beta carotene in vegetables cooked without coconut milk (with water).

Table 4.19 Total content and in vitro accessibility of all-trans-beta carotene in vegetables cooked with coconut milk - 
Table 4.20 Total content and in vitro accessibility of 9-cis $\beta$-carotene in traditionally cooked vegetables ("malluma")

Table 4.21 Total content and in vitro accessibility of 9-cis-beta carotene in traditionally cooked vegetables (stir-fried)

Table 4.22 Total content and in vitro accessibility of 9-cis--beta carotene in vegetables cooked with coconut milk

Table 4.23 Contribution to daily vitamin A requirements in children ( $1-10$ years old) by one portion of traditionally prepared vegetable relish

Table 4. 24 Total content and in vitro accessibility of lutein in fresh/blanched and traditionally prepared vegetable relishes

Table 4.25 Serum retinol concentrations (mean \pm SEM) of rats supplemented with different traditional methods of mukunuwanna preparations 


\section{LIST OF FIGURES}

Figure 2.1 Acyclic carotenoids

Figure 2.2 Cyclic carotenes

Figure 2.3 Carotenoids (Xanthophylls)

Figure 2.4 Epoxy carotenoids

Figure 2.5 Carotenoid biosynthesis from isoprenoid units.

Figure 2.6 Later stages of carotenoid biosynthesis and possible transformations of carotenoids.

Figure 2.7 Pie diagram of a typical carotenoid pattern in plasma

Figure $2.8 \quad$ Cleaving of $\beta$-carotene and resultant products

Figure 2.9 A scheme showing the newly described visual cycle of vitamin A

Figure 2.10 A schematic illustration of in vitro digestion method

Figure 3.1 HPLC chromatograms of the carotenoid standards
(a) Neoxanthin
(b) Violaxanthin
(c) $\beta$-carotene (d) Lutein

Figure $3.2 \quad$ Standard curve for $\beta$-carotene

Figure $3.3 \quad$ Standard curve for neoxanthin

Figure $3.4 \quad$ Standard curve for violaxanthin

Figure $3.5 \quad$ Standard curve for lutein

Figure 3.6 Standard curve for retinol (vitamin A)

Figure $3.7 \quad$ Standard curve for $\beta$-carotene

Figure 4.1 Separation pattern and eluting solvents of carotenoids from saponified red-fleshed papaya extract on the $\mathrm{MgO}$ : Hypoflosupercel column 
Figure 4.2 Visible absorption spectra of isolated carotenoids

(a) $\beta$-carotene (b) lycopene

Figure 4.3 HPLC chromatogram of the papaya carotenoids

Figure 4.4 Thin-layer silica-gel chromatogram of papaya carotenoids developed with $5 \%$ methanol in toluene.

Figure 4.5 Thin layer chromatogram of chemical reactions to $\beta$-caryptoxanthin and $\beta$-cryptoxanthin 5.6 epoxide from papaya (red-tleshed) developed with $5 \%$ methanol in toluene.

Figure 4.6 Microscopic view of a sections of yellow-fleshed and red-fleshed papaya.

Figure 4.7 Effects of papaya (yellow and red-lleshed) incorporated to standard diet on cardiac lipid peroxidation

Figure 4.8 Separation pattern and eluting solvents of carotenoids from saponified jakfruit extract on the $\mathrm{MgO}$ : Celite column

Figure 4.9 Thin-layer silica-gel chromatogram of carotenoids isolated from jakfruit kernel, developed with 5\% methanol in toluene.

Figure 4.10 Separation pattern and eluting solvents of carotenoids from saponified an extract of lavalu on the MgO: Hypoflosupercel column.

Figure 4.11 HPLC chromatogram (a) mixture of isolated standards

(b) carotenoid of an extract of lavalu

Figure 4.12 Thin-layer silica-gel chromatogram of carotenoids isolated from lavalu, developed with $5 \%$ methanol in toluene

Figure 4.13 Separation pattern and eluting solvents of carotenoids from unsaponified kathurumurunga extract on the $\mathrm{MgQ}$ : celite ( $1: 1)$ column 
Figure 4.14 HPLC chromatograms (a) Mixture of isolated standards

(b) carotenoids of an extract of kathurumurunga

(c) and mukunuwanna

Figure 5.1 Methylation reaction of (a) allylic hydroxyl groups

(b) for violaxanthin, which is not favorable

Figure 5.2 Epoxide-furanoid rearranement (e.g. violaxanthin )

Figure 5.3 Retinol equivalents of fruits studied calculated according to the FAO/WHO (1988) 


\section{LIST OF PLATES}

Plate 2.1 Papaya (Carica papaya) (a) yellow-tleshed papaya (b) red-fleshed papaya

Plate 2.2 Lavalu (Chrysophyllum roxhburgii)

Plate 2.3 Jakfruit (Artocurpus heterophv/lus)

Plate 2.4 Beli fruits (Aegle marmelos)

Plate 2.5 Palmyrah fruit (from Hambantota)

Plate 2. 6 Green leafy vegetables

(a) mukunuwanna (Alternanthera sessilis)

(b) gotukola (C'entella asiatica)

(c) manioc (Manihot esculenta)

(d) kathurumurunga (Sesbania grandiflora)

Plate 2. $7 \quad$ Green leafy vegetables

(a) sarana (Triathema monogyna)

(b) nivithi (Spinaceaoleracea)

(c) thampala (Amaranthus caudatus) 


\section{ABBREVIATIONS}

$\mathrm{AC}$

Acetyl-CoA

AUC

BHT

CAR

CRBP

DMAD

DW

EBP

EE

FAO

FFQ

GDP

GGDP

GLV

HIV

HKI

HPLC

ICR

IDP

IOM

IPP

IRBP
Acetone

Acetyl coenzyme A

Area under the curve

Butylated hydroxytoluene

Carotenoids

Cellular Retinal-Binding Protein

Dimethylallyl diphosphate

Dry weight

Epididymal-Binding Protein

Diethyl ether

Food and Agriculture Organisation

Food Frequency Questionnaire

Geranyl diphosphate

Geranylgenanyl diphosphate

Green leafy vegetables

Human Immuno-Deficiency Virus

Helen Keller International

High Performances Liquid Chromatography

Institute of Cancer Research

Isopentenyl diphosphate

Institute of Medicine

Isopentenyl pyro-phosphate

Interphotoreceptor Retinal-Binding Protein 


\begin{tabular}{|c|c|}
\hline LDL & Low-density lipoproteins \\
\hline LRAT & Retinol acyltransferase \\
\hline LRAT & Lecithin Retinal Acyltransferase. \\
\hline MDA & Malonaldehyde \\
\hline MPLC & Medium Pressure Liquid Chromatography \\
\hline MRI & Medical Research Institute \\
\hline ND & Not detected \\
\hline $\mathrm{OCC}$ & Open Column Chromatography \\
\hline OMNI & Opportunities for Micronutrient Intervention \\
\hline PDA & Photodiode Array \\
\hline PE & Petroleum Ether \\
\hline PFP & Palmyrah Fruit Pulp \\
\hline RA & All trans retinoic acid \\
\hline RBP & Retinol Binding Protein \\
\hline RDA & Recommended daily allowance \\
\hline RDR & Relative Dose-Response Tests \\
\hline RE & Retinol equivalent \\
\hline RGR & Retinol G protein coupled receptor \\
\hline RPE & Retinol Pigment Epithelium \\
\hline RP-HPLC & Reverse Phase High Performances Liquid Chromatography \\
\hline SD & Standard deviation \\
\hline SEM & Standard Error of Mean \\
\hline TBA & Thiobarbituric acid \\
\hline TBARS & Thiobarbituric acid reactive substances \\
\hline
\end{tabular}


TCA

TEA

TLC

UNICEF

UV

VAD

VLDL

WHO
Trichloroacetic acid

Triethylamine

Thin Layer Chromatography

United Nations Children's Fund

Ultra Violet

Vitamin A deficiency

Very low-density lipoproteins

World Health Organization 


\section{ACKNOWLEDGEMENTS}

I wish to thank all those who contributed in different ways to the work involving my thesis:

In particular, I would like to express my sincere thanks and heartfelt gratitude to my supervisor Prof E. R. Janš for his encouragement. invaluable guidance throughout the research project, suggestions on the manuscript preparation and providing opportunities to do part of this work in recognized carotenoid laboratories abroad.

I wish to thank my supervisor Prof N. D. Warnasuriya for his invaluable ideas, encouragement, constructive criticism on the manuscript preparation and continuous guidance on the clinical relevance of my work given to me during the past four years.

My thank also go to Prof. S. M. D. N. Wickramasinghe for her supervision and valuable advice đuring first two years of my project.

It is my obligation to extend my gratitude to Prof. Delia Rodriguez-Amaya, Department of Food Sciences, Faculty of Food Engineering, State University of Campinas, Brazil for giving me an opportunity to work in her world famous carotenoid laboratory and for her valuable training in carotenoid analysis and help during my stay in the Brazil.

I also wish to thank Prof. UIf Svanberg. Department of Food Science, Chalmers University of Technology, Sweden for training me in in vitro bioavailability studies, guidance, valuable advice and help given to me during my stay at Gothenburg, Sweden My sincere appreciation also extended to: International Programme for Chemical Sciences (IPICS) project SRI: 07 for equipments, chemicals, travel and training abroad and University of Sri Jayewardenepura (Research Grant No: ASP/6/PR/2000/13) for purchase of raw 
materials, rats, rat feed and costs for local travels.

Professor Malin Akerblom, the Director IPICS and her entire staff for all the support including helping me with the IPICS fellowships that enabled me to work abroad (Brazil for four months. Sweden for six months) with well respected international carotenoid researchers (Prof. Rodriguez-Amaya and Prof: Svanberg) and to present papers at International vitamin A Consultative Group meetings in Moroceo and Peru.

Staff and graduate students at Department of Food Sciences. Chalmers University of Technology, Sweden for their hospitability given to me during my stay, especially Ellen and Erika.

Staff and graduate students at Department of Food Sciences, State University of Campinas, Brazil for their friendliness, especially Patricia, for acting as my interpreter.

All members of academic and non academic staff and research students at the Department of Biochemistry, University of Sri Jayewardenepura for their support in many ways, especially Mr. Nalaka Ileperuma for helping me with HPLC equipment and Mr. Jayaweera Banda for providing me with tea and lunch when I was working after hours and week ends.

Mrs P. S. Perera for helping me with typing the thesis and Mrs. I Dayaratne for editing. My former teachers in the Department of Chemistry, University of Sri Jayewardenepura, especially, Prof. A. M. Abeysekera for his encouragement, kind advice throughout my study and for explanations of chemical reactions and Prof. W.S. Fernando for providing transport and an assistant to transport animals from MRI to the animal house.

I am forever grateful to my parents and sisters who helped me in many ways.

I DEDICATE THIS THESIS TO MY PAREN_TS 
CONTENT, BIOAVAILABILITY AND BIOCONVERSION AND

ANTIOXIDANT ACTIVITIES OF CAROTENOIDS IN SOME SRI

LANKAN FRUITS AND GREEN LEAFY VEGETABLES

UDUMALAGALA GAMAGE CHANDRIKA

\begin{abstract}
The aim of this study was to evaluate the content and bioavailability/bioconversion of pro- vitamin A carotenoids in selected fruits and green leafy vegetables (GLV) from Sri Lanka and to elucidate the effects of different processing and preparation methods. The fruits used in this study was papaya, palmyrah. jak, lavalu and beal. GLV used in this study were kathurumurunga (Seshania grandiflora), mukunuwanna (Alternathera sessilis), gotukola (C'entella asiatica), manioc (Manihot esculenta), sarana (Triathema monogyna), nivithi (Spinacea oleracea) and thampala (Amaranthus caudatus). In the case of papaya, palmyrah and jakfruits content of carotenoids were determined using MPLC and visible spectrophotometry and in the case of lavalu and GLV by HPLC method. The vitamin A and $\beta$-carotene status in Wistar rats was assessed with and without out fat in the diet in the case of papaya and mukunuwanna leaves using HPLC method. An in vitro method that simulates human digestion was used to measure the fraction of pro-vitamin A carotenoids that is release for absorption (bioaccessible) from selected GLV using HPLC method.

Separation and quantification of the carotenoids in two major varieties of Carica papaya grown in Sri Lanka indicated that red- and yellow-fleshed varieties had different carotenoid profiles. Yellow-fleshed papaya contained three major
\end{abstract}


carotenoids, i.e. $\beta$-carotene. $\beta$-cryptoxanthin and $\zeta$-carotene. In addition to these three carotenoids, red-fleshed papaya also contained lycopene and $\beta$-carotene-5,6 epoxide. It is interesting to note that red-fleshed papaya has significantly higher $\beta$-carotene and lycopene than yellow-tleshed variety. Hence the calculated mean retinol equivalent (RE) was $506.7 \pm 54.9 \mu \mathrm{gkg}^{-1}$ fresh weight (FW) in yellow-fleshed papaya, whereas in red-fleshed papaya it was $202 \pm 48 \mu \mathrm{gkg}{ }^{-1} \mathrm{FW}$. Study with Wistar rats has shown that notwithstanding the colour of the flesh a significant increase of serum vitamin $A$ is shown only if papaya is fed incorporated to standard diet $(p<0.001)$ rather than given separately (with out incorporated to standard diet). Red-fleshed variety shows higher $(66.7 \pm 4.2 \mu \mathrm{g} / \mathrm{g}) \beta$-carotene levels in the liver compared to the yellow fleshed variety $(5.4 \pm 1.0 \mu \mathrm{g} / \mathrm{g}, \mathrm{p}<0.001)$

Six carotenoids were detected in jakfruit kerncl. The carotenes are $\beta$-carotene, $\alpha$ carotene, $\beta$-zeacarotene, $\alpha$-zeacarotene, $\beta$-carotene 5, 6 epoxide and a dicarboxylic carotenoid crocetin were identified. This corresponds theoretically $25.5 \mathrm{RE} / \mathrm{l} 00 \mathrm{~g} \mathrm{FW}$. Our study indicated that jakfruit is a source of pro-vitamin A carotenoids, but not as good as papaya. Serum retinol concentrations of rats supplemented with jakfruit kernel shown to be significantly higher $(p=0.008)$ compared with control gioup. The same is true for liver retinol $(p=0.006)$. Quantification was carried out by RP-HPLC. This results shows biological conversion of pro-vitamin $A$ in jakfruit kernel appears satisfactory. Thus increased consumption of ripe jakfruits could be advocated as a part of a strategy to prevent and control of vitamin A deficiency in Sri Lanka. 
Four major carotenoids were detected in palmyrah fruit pulp (PFP). The carotenoids are $\alpha$-carotene, $\zeta$-carotene. lycopene and $\beta$-zeacarotene and this corresponds to 22.3 RE/ $100 \mathrm{~g} F \mathrm{~F}$. The results of in vivo bioavailability and bioconversion studied showed that pro-vitamin A carotenoids from PFP were also bioavailable and bioconvertible.

The major carotenoid in lavalu (Chrysophyllum roxhhurgii) was trans-violaxanthin (113 mg.kg-1.63\%). Also present was cis-violaxanthin (19\%), neoxanthin (3\%). $\beta$ cryptoxanthin monoepoxide $(11 \%)$, lutein. $\beta$-cryptoxanthin. $\zeta$-carotene and $\beta$-carotene. The retinol equivalent of the pulp was only $13.8 \mathrm{RE} / 100 \mathrm{~g} \mathrm{FW}$. The study shows that lavalu is not a good source of pro vitamin A. Further the structural properties of the carotenoids make bioconversion studies with animals or humans futile. So that the best use of the lavalu carotenoids is as a food colourent for oil based foods.

In the case of beli (Aegle marmelos) there were only trace amount of caroenoids and canot be used as a pro vitamin A supplement.

The all-trans- $\beta$-carotene content in fresh GLV ranged from $03.1 \mu \mathrm{g} / \mathrm{g} \mathrm{FW}$ in leaves of mukunuwanna to $133.8 \mu \mathrm{g} / \mathrm{g} \mathrm{FW}$ in the thampala. Cooking of fresh leaves resulted in some losses of all-trans- $\beta$-carotene and retention ranging from 56 to $76 \%$ in the malluma and 27 to $73 \%$ in the fried preparation. Cooking with water or coconut milk resulted in retentions ranging from 36 to $88 \%$. The in vitro accessibility of all-trans- $\beta$ carotene in cooked vegetables ranged from 14 to $43 \%$ in malluma, and from 12 to $36 \%$ in the fried preparation. In the GLV cooked with coconut milk the in vitro accessibility ranged from 12 to $26 \%$ compared with 4 to $8 \%$ when cooked with water. The $\beta$ carotene content, retention and in vitro accessibility widely varied between different varieties of green leaves. The three types of different traditional cooking procedures 
show about the same retention. Preparations with oil. scraped coconut and coconut milk had improved in vitro $\beta$-carotene accessibility.

In conclusion, the green leafy vegetables and truits studied have variable contents and in vitro accessibility of pro-vitamin A carotenoids and thus contribute in various degrees to recommended daily allowance (RDA) of vitamin A. For green leafy vegetables such as kathurumurunga, mukunuwanna, manioc, gotukola, sarana, thampala an adequate contribution to RDA of vitamin A can be obtained by consumption of green leafy vegetables $(100 \mathrm{~g}, \mathrm{FW})$ with high pro-vitamin A content judging from in vitro accessibility and traditional preparation methods of Sri Lanka with addition of coconut, coconut milk or coconut oil.

None of fruits studied would cover the total vitamin A requirement if consumed in normal amounts. Papaya, jak and palmyrah should be considered as good sources of pro-vitamin A carotenoids, as they would be a sound vitamin A contributing complement to the diet. This study also revealed that some fruits such as lavalu and beli are not good sources of pro-vitamin A as believed by the general population. These findings can be useful in dietary intervention programmes to alleviate vitamin A deficiency in Sri Lanka as well as other developing countries. 